\title{
A predominância da vertente "alunos em tempo integral" nas discussões sobre o tema da educação integral em tempo integral
}

BRUNO ADRIANO RODRIGUES DA SILVA Universidade Federal de Lavras, Lavras, MG, Brasil

\section{RESUMO}

Nas discussões sobre o tema da educação integral em tempo integral identificamos duas vertentes: uma que amplia o tempo de permanência dos alunos na escola, tendo-os como foco dos investimentos administrativos, pedagógicos e financeiros, e outra que tem como foco desses investimentos toda a instituição escolar. Este artigo tem o objetivo de analisar a predominância da primeira vertente sobre a segunda, de acordo com um olhar sócio-histórico, em virtude do desenvolvimento, pelo Governo Federal, do Programa Mais Educação. Analisamos as experiências escolares e as legislações referentes ao tema e as produções da sociedade civil organizada que fundamentam a primeira vertente. Concluímos que estamos diante de um debate em aberto no campo da educação, em que pese à predominância de uma vertente sobre a outra e que essa vertente predominante é a expressão de uma nova configuração na oferta do direito à educação.

PALAVRAS-CHAVE

educação integral; Programa Mais Educação; direito à educação. 


\title{
THE PREVALENCE OF THE "FULL-TIME STUDENTS" ASPECT IN THE DISCUSSIONS ON FULL-TIME INTEGRATED EDUCATION
}

\begin{abstract}
Two aspects were identified in discussions about the theme of Full-Time Integral Education: One of them focuses on the length of time students spend at school. In this case, these students are the focus of administrative, educational and financial investments. The second aspect has its focus on the investments in the whole school institution. This article aims at analyzing the prevalence of the first aspect over the second, according to a socio-historical view, due to the development, by the Federal Government, of the More Education Program (Programa Mais Educação). We have analyzed the school experiences and legislation on the subject as well as the production of civil society organizations that ground this aspect. We can say that we are facing an open debate in the field of education, despite the predominance of an aspect over the other and that the aforementioned predominant aspect is the expression of a new configuration in the provision of the right to education.
\end{abstract}

KEYWORDS

full time integral education; More Education Program; right to education.

\section{LA PREDOMINANCIA DE LA VERTIENTE “ESTUDIANTES EN TIEMPO INTEGRAL" EN LOS DEBATES SOBRE EL TEMA DE LA EDUCACIÓN INTEGRAL EN TIEMPO INTEGRAL}

\section{RESUMEN}

En las discusiones sobre el tema de la educación integral de tiempo integral identificamos dos vertientes: una que extiende la duración de la estancia de los estudiantes en la escuela, y se concentra en las inversiones administrativas, educativas y financieras, y otra que se concentra en estas inversiones de toda la institución escolar. Este artículo tiene como objetivo analizar la predominancia de la primera vertiente sobre la segunda, de acuerdo con un aspecto socio-histórico, debido al desarrollo, por parte del Gobierno Federal, del Programa Más Educación. Analizamos las experiencias escolares y las legislaciones sobre el tema, así como la producción de las organizaciones de la sociedad civil que apoyan esta vertiente. Podemos afirmar que estamos frente a un debate abierto en el campo de la educación, a pesar del predominio de una vertiente sobre la otra y que esa vertiente predominante es la expresión de una nueva configuración en la oferta del derecho a la educación.

PALABRAS CLAVE

educación integral; Programa Mais Educação; derecho a la educación. 


\section{INTRODUÇÃO}

Este artigo tem o objetivo de analisar a predominância da vertente "alunos em tempo integral" sobre a vertente "escolas em tempo integral", em virtude do desenvolvimento, pelo Ministério da Educação (MEC) em parceria com outros ministérios, desde 2007, de um programa que estimula as políticas municipais e estaduais de educação integral em tempo integral a investirem apenas no aluno e não nas escolas. Esse programa é denominado de Mais Educação e funciona conforme o modelo que preconiza parcerias com instituições do entorno da escola, o desenvolvimento de oficinas temáticas no contraturno escolar com base no trabalho voluntário (Cavaliere, 2009).

Utilizaremos um referencial teórico composto de uma categorização de cunho histórico e de uma categorização sociológica que defende um embate entre as duas vertentes citadas, que na atualidade constituem a temática da educação integral em tempo integral (Cavaliere, 2009; Coelho, 2009). Também faremos uso das categorias "aparelhos privados de hegemonia", "intelectuais" e "escola unitária" (Gramsci, 2006, 2007) para analisar o tema, notadamente naquilo que diz respeito à vertente "alunos em tempo integral".

O material empírico utilizado na análise foi produzido a partir de uma revisão de literatura sobre as experiências de educação integral em tempo integral de maior relevo no cenário brasileiro, pelo levantamento e seleção da legislação educacional e instrumentos normativos relativos ao tema e por revisão de literatura acerca das formulações oriundas das organizações da sociedade civil que fundamentam a vertente predominante.

\section{“ESCOLAS EM TEMPO INTEGRAL" VERSUS "ALUNOS EM TEMPO INTEGRAL"}

$\mathrm{Na}$ história da educação brasileira, o tema da educação integral em tempo integral encontra-se presente de modo recorrente, embora seja utilizado a partir de matrizes ideológicas diferentes e às vezes antagônicas. Podemos citar: as conservadoras, que defendiam a "espiritualidade, o nacionalismo-cívico e a disciplina" presentes, por exemplo, nas experiências educacionais desenvolvidas pela Ação Integralista Brasileira e por diferentes ordens religiosas; as liberais, que defendiam a igualdade educacional como uma das formas de sustentação da igualdade democrática — caso, por exemplo, das experiências educacionais vinculadas aos pioneiros da Educação Nova no Brasil e de toda a tradição decorrente desse movimento a partir da década de $1920 ;^{1}$ e as socialistas, que baseavam suas experiências no entendimento de que educação deveria ser vista como um meio de emancipação social, um instrumento

1 Utilizamos a década de 1920 como referência em virtude dos embates já constituídos no âmbito da Associação Brasileira de Educação, cuja tradição liberal, anos depois, deu origem ao Movimento dos Pioneiros da Escola Nova (1932), que, apesar de não ser homogêneo, já atuava em bloco na defesa de uma escola pública e universal. Para mais informações, ver Cury (1984). 
de construção de igualdades - caso das escolas sindicais vinculadas aos grupos anarquistas e marxistas (Coelho, 2009, p. 88).

Já na atualidade identificamos duas "vertentes": aquela que investe em mudanças estruturais (físicas, administrativas e pedagógicas) nas unidades escolares, de modo que elas possam oferecer condições compatíveis com a presença de alunos e professores em tempo integral, chamada de "escolas em tempo integral", e outra que procura articular distintas instituições e projetos da sociedade civil organizada que ofereçam atividades apenas para parte dos alunos no turno alternativo às aulas $\mathrm{e}$ não necessariamente no espaço escolar, denominada de "alunos em tempo integral" (Cavaliere, 2009).

A primeira vertente aproxima-se da matriz liberal e das experiências escolares voltadas para a educação integral em tempo integral, desenvolvidas por Anísio Teixeira. Para esse intelectual do campo da educação, a questão não estava apenas no redirecionamento das atividades pedagógicas em relação aos alunos, mas na capacidade de atendimento da escola pública, isto é, oportunidades iguais para todos e sem nenhum tipo de distinção (Teixeira, 1997).

A segunda vertente possui como fundamentação teórica os conceitos "educação permanente" e "cidade educativa". Originalmente eles foram publicados no relatório "Aprender a ser", produzido pela Organização das Nações Unidas para a Educação, a Ciência e a Cultura (UNESCO), no início dos anos de 1970, que recomendava a articulação entre a "educação extraescolar" e as próprias instituições de "ensino metódico" (Faure, 1972). Nesse relatório, o "desprezo" por aquilo que acontecia fora das instituições escolares deveria ser considerado apenas um "vulto do passado", que não deveria "corresponder à atitude de nenhum pedagogo progressista”, na medida em que a educação deveria ser pensada de forma permanente e por diferentes instituições, mas sem renunciar "[...] à escola, como elemento essencial, ainda que não exclusivo, da educação" (Faure, 1972, p. 33).

Esses conceitos foram associados - no relatório da UNESCO, "Educação: um tesouro a descobrir" (1996) - à ideia de "uma sociedade educativa", isto é: "educação ao longo de toda a vida dadas as vantagens que oferece em matéria de flexibilidade, diversidade e acessibilidade no tempo e no espaço" (Delors et al., 2002, p. 18). Nesse momento, o protagonismo da escola no processo educacional dos indivíduos foi relativizado, em virtude de uma transformação:

[...] as possibilidades de aprender oferecidas pela sociedade exterior à escola multiplicam-se, em todos os domínios, enquanto a noção de qualificação, no sentido tradicional, é substituída em muitos setores modernos de atividade, pelas noções de competência evolutiva e capacidade de adaptação. (Delors et al., 2002, p. 103)

A realização do I Congresso Internacional das Cidades Educadoras, que originou a Associação Internacional das Cidades Educadoras (AICE), deflagradora, em 1994, de sua carta de princípios, também fundamentou, teoricamente, a vertente "alunos em tempo integral", em especial por conta do conceito genérico que apregoava à cidade um suposto protagonismo educacional na vida dos indiví- 
duos. Tratava-se mais de retirar a centralidade escolar e repassá-la para o contexto das cidades: "O direito a uma cidade educadora é proposto como uma extensão do direito fundamental de todos os indivíduos à educação" (CENPEC, 2006a, p. 158).

É possível afirmarmos que essa vertente, em virtude de sua fundamentação, afasta-se dos preceitos liberais que identificam a instituição escolar como o móvel responsável pela viabilidade da educação integral em tempo integral, na medida em que ela acredita que outras instituições, por meio de parcerias, também possam compartilhar com a escola o protagonismo educacional na vida dos indivíduos. É por isso que essa vertente desloca seus investimentos para parte da instituição escolar, o pedagógico, com foco apenas no aluno (desconsiderando o professor) e nas supostas potencialidades dessas parcerias.

Acreditamos que aqui no Brasil dois foram os fatores explicativos desse afastamento no sentido apontado pelas reformas neoliberais nos anos de 1990:i) a ampla organização da sociedade civil, notadamente do setor privado (grandes empresas ligadas aos diferentes ramos da economia, mas em especial ao setor financeiro), e a sua maior influência no aparelho de Estado fazendo dele um agente direto de seus interesses; ii) e, por consequência disso, a revisão da amplitude das políticas sociais, entre elas a educação, como forma de garantir, apenas, níveis toleráveis de desigualdades para que as medidas de ajuste fiscal pudessem ocorrer em benefício desse mesmo setor privado (Martins, 2007).

\section{O QUE NOS DIZEM AS EXPERIÊNCIAS DE MAIOR RELEVO NO CENÁRIO NACIONAL}

Anísio Teixeira, ainda nos anos de 1930, quando inspetor de educação pública do Distrito Federal (Rio de Janeiro), no governo de Pedro Ernesto (19311936), desenvolveu um programa educacional com "cinco escolas experimentais" articulando atividades escolares, manuais, culturais, de educação física, de rádio, comunitárias, com uma perspectiva universalista para a etapa primária da educação (Teixeira, 1997).

O mesmo Anísio Teixeira, alguns anos depois, mais precisamente no início da década de 1950, idealizou o Centro Educacional Carneiro Ribeiro em Salvador, Bahia, primeira experiência do modelo "escolas classes/escolas parque", centros educacionais divididos em dois pavilhões funcionando em horário integral com $\mathrm{o}$ incremento de atividades artísticas, culturais e profissionais oferecidas às classes populares no ensino primário (Eboli, 1969). Essa experiência também foi desenvolvida no Distrito Federal, em Brasília, nos anos de 1960.

Outra experiência importante foi desenvolvida no estado do Rio de Janeiro nos anos de 1980. Sob a influência de Anísio Teixeira, Darcy Ribeiro desenvolveu uma política educacional voltada para a educação integral que, entre várias ações, criava o Centro Integrado de Educação Pública (CIEP): escolas de horário integral preparadas de maneira pedagógica e em sua infraestrutura física e administrativa para atender às demandas das classes populares (Ribeiro, 1986). 
Ao longo das décadas de 1980 e 1990 foram desenvolvidos programas educacionais que também tinham como característica a preocupação com toda a estrutura de funcionamento da escola por influência direta daquelas iniciativas desenvolvidas por Anísio Teixeira. Esse era o caso de experiências como: a desenvolvida em Curitiba (PR), o Centro de Educação Integral (CEI); do programa implementado pelo Governo Federal, o Centro Integrado de Apoio à Criança e ao Adolescente (CIAC) e posteriormente o Centro de Atenção Integral à Criança e ao Adolescente (CAIC); da iniciativa do estado do Rio Grande do Sul, que também desenvolveu o modelo adotado no Rio de Janeiro por Darcy Ribeiro, o CIEP, assim como na cidade de Americana (SP). Essas iniciativas podem ser vinculadas à vertente "escolas em tempo integral" (Cavaliere, 2011).

Em contrapartida, as iniciativas relacionadas à vertente "alunos em tempo integral” também estão presentes na história, caso dos ginásios estaduais vocacionais criados em 1961 em São Paulo, inspirados em uma escola renovada que aliasse "o plano de cultura geral e de cultura técnica" para "a formação integral" do aluno. Essa experiência também propunha uma escola com um forte vínculo comunitário e com um plano administrativo e pedagógico próprio para seu desenvolvimento. Até 1969, que foi o ano de seu término, algumas injunções político-administrativas foram determinantes para que diferentes problemas prejudicassem o seu desenvolvimento, inclusive a falta de escolas com estruturas de funcionamento adequadas ao seu modelo (Ferreira, 2007).

De 1983 até 1987 foi desenvolvido também no estado de São Paulo o Programa de Formação Integral da Criança (PROFIC). Ele funcionava como um aporte financeiro que adicionava às prefeituras locais verbas para apoiar as experiências voltadas para o tempo integral na escola e "praticava a ideia de que a extensão do tempo poderia ser feita em diferentes espaços, sob a coordenação das prefeituras, caracterizando um movimento centrífugo em relação à unidade escolar"(Cavaliere, 2009, p. 52).

Mais recentemente, outras iniciativas de destaque fundamentadas na vertente "alunos em tempo integral" ingressam na cena educacional, principalmente pela influência da legislação, como veremos na próxima seção. No âmbito das políticas estaduais, podemos citar: Santa Catarina, onde foram desenvolvidas as Escolas Públicas Integradas, a partir de 2005; Minas Gerais, onde, também em 2005, foi desenvolvido o Programa Aluno de Tempo Integral; e São Paulo, que em 2006 criou as Escolas de Tempo Integral. No âmbito das políticas municipais, merecem destaque: Belo Horizonte (MG), que em 2005 criou o Programa Educação em Tempo Integral, posteriormente transformado em Escola Integrada; São Paulo (SP), que, também em 2005, desenvolveu o Programa São Paulo é uma Escola; e outras iniciativas municipais, como em Recife (PE), Apucarana, Cascavel e Pato Branco (PR) e Araruama (RJ) (Cavaliere, 2007).

Os números contidos no censo escolar também são indicadores da presença predominante da vertente "alunos em tempo integral", na medida em que revelam o impacto crescente do Programa Mais Educação: em 2010, os dados indicam um número ainda reduzido de alunos matriculados em programas que visavam ao aumento do tempo diário de permanência nas escolas, por meio da educação 
integral, apenas 414.889 (1,5\% do total); em 2011 os dados sugerem um aumento, já que 1.686.407 (6,4\% do total) de estudantes estavam matriculados; em 2012, os dados também sugerem aumento, 2.101 .735 (8,2\% do total) (Brasil, 2011, 2012, 2013). Para os próximos anos, a tendência é de crescimento, visto que as metas sobre essa matéria, contidas no novo Plano Nacional de Educação (PNE) (lei n. 13.005/2014), cuja projeção, em seu período de vigência (2014/2024), é de 50\% das escolas públicas oferecendo educação integral em tempo integral para $25 \%$ das matrículas do ensina básico (Brasil, 2014a).

Podemos perceber com essa revisão de literatura que existe uma predominância da vertente "escolas em tempo integral" até sua transição entre os anos 1980/1990 e que, a partir desse momento, ganham destaque no cenário nacional as experiências elaboradas com base na vertente "alunos em tempo integral", culminando com sua ascensão no final da primeira década do século XXI, em virtude do Programa Mais Educação.

Essa modificação é perfeitamente compatível com a revisão presente nas políticas sociais em um contexto de reformas neoliberais a partir de 1990. Se outrora a perspectiva era a de gerar oportunidades iguais de acesso à educação por meio de uma escola compatível com isso, na atualidade o que predomina são ações por parte do Estado, caso do Programa Mais Educação, que buscam equacionar as desigualdades sociais sem uma preocupação mais ampla, isto é, com o próprio processo de produção de desigualdades pelas escolas.

\section{O QUE NOS DIZEM AS LEGISLAÇÕES REFERENTES AO TEMA}

A Lei de Diretrizes e Bases (LDB), lei n. 9.394/1996, trata da ampliação da jornada escolar a partir do artigo 34 , parágrafo $2^{\circ}$, e do artigo 87 , parágrafo $5^{\circ}$, ficando essa ampliação a critério dos estabelecimentos de ensino. Não se especifica como tal jornada será ampliada; no entanto, o artigo $3^{\circ}$, incisos X e XI, nos fornecem pistas sobre isso: "Valorização da experiência extraescolar"; "Vinculação entre a educação escolar, o trabalho e as práticas sociais" (Brasil, 1996).

Aliado a esse mecanismo, o Estatuto da Criança e do Adolescente (ECA), regulamentado pela lei n. 8.069/1990, afirma em seu Capítulo V que a criança possui o direito à educação, o que visa ao seu pleno desenvolvimento como cidadão e à qualificação para o trabalho (Brasil, 1990).

O PNE, lei n. 10.172/2001, estabelece duas metas específicas para a ampliação da jornada escolar no ensino fundamental que conjugam a sua progressiva ampliação para pelo menos sete horas diárias e a focalização dessa ampliação por meio de atividades de alimentação, reforço escolar, esporte e artes, em um público específico, preferencialmente aquele associado aos programas de redistribuição de renda, caso do Programa Bolsa Família (Brasil, 2001).

O Fundo de Manutenção e Desenvolvimento da Educação Básica e de Valorização dos Profissionais da Educação (FUNDEB), lei n. 11.494/2007, viabilizou, em parte, a demanda financeira para essa política de ampliação da jornada escolar, na medida em que foram atribuídas ponderações anuais para o aumento dos investimentos em alunos matriculados nos sistemas educacionais, 
em diferentes níveis e modalidades, que adotassem a ampliação da jornada escolar. O FUNDEB também regulamentou o número de horas diárias, igual ou superior a sete (Brasil, 2007a).

O Plano de Desenvolvimento da Educação (PDE), lançado pelo Governo Federal em 2007, que consistia em um plano gerencial para a educação, atendia em primeiro lugar as reivindicações do setor privado, organizado em torno do Movimento Todos Pela Educação (TPE) $)^{2}$ e, em segundo lugar, procurava cumprir as metas previstas pelo PNE, em seu prazo de vigência de dez anos (Saviani, 2007). Entre as metas relacionadas à ampliação da jornada escolar, vale destacarmos: a adoção do reforço escolar no contraturno, a ampliação das possibilidades de permanência do aluno sob a responsabilidade da escola para além da jornada regular, a integração dos programas da área da educação com os de outras áreas (saúde, esporte, assistência social, cultura, entre outras), a transformação da escola em um espaço comunitário e a manutenção ou recuperação daqueles espaços e equipamentos públicos da cidade que possam ser utilizados pela comunidade escolar e a realização de parcerias externas à comunidade escolar visando à melhoria da infraestrutura da escola ou a promoção de projetos socioculturais e ações educativas (Brasil, 2007b).

Como síntese para a execução dessas metas, o Programa Mais Educação foi instituído pela portaria interministerial n. 17/2007 estabelecendo que: a ampliação da jornada escolar deve ocorrer por meio da introdução de espaços físicos distintos ao da escola e de agentes educativos distintos aos professores (tendo como sustentação a lei do voluntariado 9.608/1998, conforme pode ser inferido a partir do artigo $2^{\circ}$, parágrafo VII, dessa portaria); a escola deve cumprir as funções de proteção social, assistência social, saúde e alimentação. A base de sustentação institucional do Programa Mais Educação estava na articulação entre os ministérios da Educação, da Cultura, do Desenvolvimento Social e Combate à Fome, do Esporte e a Presidência da República, entes federados (estados e municípios), instituições públicas e privadas localizadas na sociedade civil (Brasil, 2007c).

Após essa portaria, o Governo Federal instituiu o decreto-lei n. 7.083/2010, que também dispunha sobre o Programa Mais Educação. Ele foi apresentado de maneira mais propositiva, definindo o significado do tempo integral na educação básica, como a jornada escolar seria ampliada, os conteúdos e as funções escolares, as parcerias e a constituição do território educativo com a comunidade, as práticas de sustentabilidade, os direitos humanos, entre outros. Ele também ampliou a base de sustentação institucional do Programa Mais Educação; além dos ministérios já descritos, foram incorporados os ministérios da Saúde, do Meio Ambiente e da Ciência e Tecnologia (Brasil, 2010a).

2 Organismo criado pelo setor empresarial (Fundação Itaú Social, Grupo Gerdau, Instituto Camargo Corrêa, Fundação Bradesco, contando com parceria da Rede Globo, Fundação Ayrton Senna e apoio da Fundação Victor Civita, Instituto Paulo Montenegro, entre outras empresas líderes, parceiras e apoiadoras), em 2006, com vista a empreender um projeto educacional para o país atuando diretamente por meio da escola pública. 
Nesse mesmo ano, o Governo Federal, por meio do Conselho Nacional de Educação (CNE), formulou as Diretrizes Nacionais para o Ensino Fundamental de nove anos, resolução n. 7/2010. Esse documento, em articulação com as Diretrizes Curriculares Gerais para a Educação Básica, normatizadas pelo parecer CNE/CEB n. 7/2010 e pela resolução CNE/CEB n. 4/2010, reunia "princípios, fundamentos e procedimentos" para orientação, elaboração e desenvolvimento de políticas educacionais com as orientações curriculares nacionais, estaduais, municipais e com o projeto político-pedagógico das escolas. Nesse documento, o tema da educação integral em tempo integral apareceu de acordo com a necessidade da progressiva ampliação do tempo de permanência dos alunos na escola (as mesmas sete horas já citadas), baseada na diversificação de espaços e agentes educacionais (Brasil, 2010b).

Mais recentemente, as metas presentes o novo PNE (lei 13.005/2014), citadas na seção anterior, reforçam a compreensão já instaurada da legislação brasileira acerca de vertente "alunos em tempo integral", na medida em que elas tomam como referência o Programa Mais Educação.

Como dissemos, o aumento das práticas voltadas à educação integral em tempo integral pelo país e a própria modificação no perfil dessas práticas, adaptadas à vertente "alunos em tempo integral", estão ancorados na indução realizada pelo Governo Federal nos últimos anos por meio do Programa Mais Educação, em especial na primeira década do século XXI. O movimento legislativo, conforme expressamos, é o que sustenta isso.

Vale destacar também os mecanismos presentes nas diferentes legislações que induzem a escola a procurar fora de seus limites a solução para os entraves pertinentes ao desenvolvimento da educação integral em tempo integral. Esse movimento é compatível com o ideário presente no plano de metas Compromisso Todos Pela Educação, idealizado e fundamentado para atender aos interesses do setor empresarial naquilo que tange ao seu projeto para a educação brasileira tendo como referência de atuação a escola pública.

\section{O QUE AS ORGANIZAÇÕES DA SOCIEDADE CIVIL NOS DIZEM SOBRE A TEMÁTICA}

No âmbito da sociedade civil organizada é crescente o interesse por discussões afeitas à educação, inclusive de organizações vinculadas a empresas privadas que atuam por meio do TPE formulando programas educacionais para serem desenvolvidos nas escolas públicas. O Programa Mais Educação é resultado desse modo de se formular e desenvolver programas educacionais (Silva, 2013).

Mais precisamente, analisaremos as três organizações que contribuíram com a fundamentação do Programa Mais Educação: o Centro de Estudos e Pesquisas em Educação, cultura e Ação Comunitária (CENPEC); a Associação Cidade Escola Aprendiz; e o Instituto Paulo Freire. Todas elas possuem peculiaridades, no entanto também possuem em comum a tendência à vertente "alunos em tempo integral" (Silva, 2013). 


\section{UMA INCUBADORA DE EXPERIÊNCIAS PARA O DESENVOLVIMENTO DE UMA PERSPECTIVA DE EDUCAÇÃO INTEGRAL: O CENPEC}

O CENPEC apresenta-se enquanto uma Organização da Sociedade Civil de Interesse Público (OSCIP) e possui como foco as políticas de assistência social direcionadas à educação. Atua como um aparelho privado de hegemonia no campo da educação de uma instituição do setor financeiro, o Itaú Unibanco Holding S. A., prestando assessoria técnica em suas ações.

Os aparelhos privados de hegemonia são a vertebracão da sociedade civil e se constituem das instâncias associativas que, formalmente distintas da organização das empresas e das instituições estatais, apresentam-se como associatividade voluntaria sob inúmeros formatos [...]. Não são homogêneos em sua composição e se apresentam muitas vezes como totalmente descolados da organização econômico-política da vida social. (Fontes, 2010, p. 133)

O CENPEC é liderado pela socióloga Maria Alice Setúbal, uma intelectual orgânica do Itaú Unibanco Holding S. A. (parente direta do presidente dessa instituição financiadora do CENPEC, Roberto Egydio Setúbal) com atuação em organismos multilaterais, como o Fundo das Nações Unidas para Infância (UNI$\mathrm{CEF}$ ), o MEC e outras importantes organizações da sociedade civil. A concepção de Gramsci (2006, p. 15) sobre os intelectuais nos ajuda a melhor compreender a participação de Maria Alice nos assuntos afeitos a essa organização do setor financeiro, uma vez que estamos nos referindo a um indivíduo que dialoga em torno dos interesses e demandas dessa instituição. Todo grupo social cria para si, "[...] organicamente, uma ou mais camadas de intelectuais que lhe dão homogeinidade e consciência da própria função, não apenas no campo econômico, mas também no social e no político [...]”.

Desde o início dos anos de 1990 que o CENPEC atua como uma incubadora $^{3}$ de ações e projetos socioeducativos desenvolvidos por outras organizações da sociedade civil valendo-se da coordenação técnica de conhecida premiação bienal oferecida pela Fundação Itaú Social em parceria com o UNICEF, uma das ações previstas pelo Programa Educação \& Participação. ${ }^{4}$

3 O CENPEC participa diretamente de um movimento que possibilita que experiências ligadas ao campo educacional, elaboradas por seus congêneres, possam se desenvolve, ganhando assim possibilidades de difusão. Essas condições vão desde incentivos financeiros até assessorias com fins promocionais. Defendemos essa ideia principalmente pelo fato de o CENPEC possuir como financiadora uma empresa privada de grande porte do setor financeiro, algo que se relaciona com a origem do termo "incubadora", próprio do mundo corporativo, como a experiência desenvolvida pelo Serviço Brasileiro de apoio às Micro e Pequenas Empresas (SEBRAE).

4 Além dessa premiação, esse programa ainda conta com as seguintes ações: encontros regionais de formação, Projeto Tecendo Redes, estudos e pesquisas, publicações, site e boletim eletrônico (CENPEC, 2008). 
Em 1995, na primeira edição dessa premiação, o CENPEC focalizou o que denominava de ações não escolares com a publicação de um guia de ações complementares que difundia a importância de atividades desenvolvidas fora da rede escolar, realizadas por organizações da sociedade civil que visavam ao avanço da educação pública. Esse parâmetro de ação avançou até o final dos anos de 1990, quando o CENPEC ingressou em um novo momento (CENPEC, 2007b, 2008).

No ano de 1999, essa organização publicou o estudo Guia de referência: educação integral, um levantamento de experiências e publicações sobre o tema que fora realizado somente em bibliotecas e bancos de teses e dissertações do estado de São Paulo. Concluía-se que a temática da educação integral, em que pese o fato de apenas resvalar nas referências levantadas, durante os anos de 1990, não havia merecido a atenção dos pesquisadores do campo da educação. Esse guia preconizava, naquele momento, um vazio conceitual, e isso abria espaço para a difusão da perspectiva do CENPEC, que já estava voltada para a vertente "alunos em tempo integral".

Em 2001, a temática da premiação Itaú/UNICEF, "O direito de aprender", possuía como mote a mobilização social em torno da situação educacional do país. Nessa premiação, o direito de aprender na escola, apesar de aparecer como um dos objetivos da mobilização realizada pelo CENPEC, foi colocado em segundo plano, diante do direito de aprender em outros espaços educativos. Partia-se da premissa de que o direito ao acesso à escolarização havia sido universalizado e que a premência agora estaria na ampliação dos direitos sociais como forma de garantir a permanência na escola pública.

Por esse motivo, a introdução de novos espaços educativos ao processo educacional foi estabelecida como mote da premiação seguinte. Realizada em 2003, "Muitos lugares para aprender", destacava a importância da diversificação dos espaços de aprendizagem e consequentemente dos agentes educacionais como forma de garantia da cidadania para aqueles que assim necessitassem (CENPEC, 2003).

No ano de 2005, essa premiação apresentou para o debate a temática "Tecendo redes” e tinha a finalidade de agregar à perspectiva de educação integral um sentido multissetorial, imputando às políticas educacionais novos sentidos $\mathrm{e}$, principalmente, novas funções:

[...] não bastam mais políticas fatiadas (educação, assistência social, cultura, esporte...), são necessárias articulações e propósitos multissetoriais conjugados. Também não bastam ações estatais, são necessários o envolvimento e a pró-atividade da comunidade local e da sociedade. (CENPEC, 2008, p. 25)

Ainda em 2006, essa mesma organização publicou os seus dois primeiros cadernos temáticos com o intuito de subsidiar as discussões sobre a educação integral. O primeiro dos cadernos — "Educação e cidade" (2006a) — realizava uma discussão sobre o potencial educativo existente nas cidades, tendo como base a Carta de princípios da AICE. Essa publicação trazia à tona um elemento significativo: a escola como a instituição responsável pela problematização da cidade enquanto espaço educativo. São apresentadas experiências bem-sucedidas com ênfase nas 
ações originalmente elaboradas, por meio de parcerias entre instituições escolares e organizações não governamentais.

Nesse caderno, afirma-se que o conceito de educação do CENPEC supera o conceito de rede escolar, no entanto, ao longo de toda a publicação, o que percebermos é um atrelamento das discussões sobre o conceito de cidade educadora à ação escolar, assim como preconiza o já citado relatório "Aprender a ser" (Faure, 1972). Isso poderia ser considerado um paradoxo, caso o conceito de educação defendido pelo CENPEC não oscilasse tanto ao longo dessa obra: ao mesmo tempo em que afirma "superar" a ideia de rede escolar, necessita dessa rede para ter acesso ao seu público prioritário: as classes populares.

O segundo caderno temático - "Educação integral" (2006b) - trouxe para a discussão a perspectiva de educação integral do CENPEC, ou seja, um trabalho totalmente destinado aos debates sobre ampliação dos espaços, dos agentes e das funções pertinentes à escola pública. Em primeiro lugar, procurava-se "repensar" a instituição escolar, uma vez que era detectado que a política educacional (ou qualquer outra política social), por si só, não comportava as demandas daquela perspectiva de educação integral. Para o CENPEC, somente uma ação intersetorial (entre diversas áreas da política social, diferentes espaços educativos e diferentes agentes educacionais) poderia dar conta das necessidades contemporâneas da escola pública em relação ao atendimento das classes populares.

Em 2007, a premiação oferecida pelo Banco Itaú em parceria com o UNI$\mathrm{CEF}$ versava sobre o movimento TPE. Esse prêmio foi destinado às organizações da sociedade civil que desenvolviam a educação integral em parceria com escolas públicas. É importante ressaltar a sintonia entre essa premiação e o organismo, com bases empresariais, lançado no ano anterior, em 2006, no Museu do Ipiranga em São Paulo, o TPE. Além disso, à época de sua criação, a presidenta de seu comitê executivo, Milu Villela, também exercia suas funções como presidenta da Fundação Itaú Cultural e como a maior acionista individual desse mesmo banco, que é parte integrante desse movimento.

Na premiação seguinte, em 2009, o aprofundamento deu-se em torno do conceito de educação integral defendido pelo CENPEC, principalmente pela contribuição de outros tipos de ações políticas oriundas de organizações da sociedade civil, mais especificamente de ações assistenciais no campo do esporte, da cultura, da alimentação, entre outros, em articulação com a escola pública. Esse prêmio procurava reforçar o entendimento intersetorial presente no conceito do CENPEC.

Mais recentemente, na edição dessa premiação, "Educação integral: experiências que transformam" (2011), foi possível perceber o investimento na consolidação da educação integral, vista como estratégica para o desenvolvimento de políticas educacionais visando à qualidade da educação pública. Mais especificamente uma publicação do CENPEC, lançada em 2011, assim define as "tendências para a educação integral":

Em sua trajetória, o Prêmio Itaú-Unicef, sem perder de vista as organizações sociais, buscou aliar a escola e os inúmeros outros atores e espaços presentes na concretização de uma educação integral. Tendências para Educação Inte- 
gral é uma publicação que compreende a educação integral como uma política fundamentada na concepção de uma educação que desenvolva na sua integralidade as dimensões física, afetiva, cognitiva, intelectual e ética de que nossas crianças e adolescentes precisam e que desejam, além de ser uma resposta da maior importância à proteção integral devido ao grupo infantojuvenil. Ao considerar todas essas dimensões, a educação integral traz relevante contribuição para a qualidade da educação, o que pode ser demonstrado pelo Ideb. (CENPEC, 2011, p. 10)

Todas essas ações e publicações do CENPEC tratam dos temas pertinentes a um entendimento que confere ao tema da educação integral em tempo integral um caráter focalizado, centrado em grupos específicos (pobres) apenas, que não atingem aspectos que poderiam alterar o quadro de exclusão produzido pela escola pública. Tais como: espaço físico estruturado; remuneração condizente; democracia interna; condições de funcionamento compatíveis com as demandas das escolas que, em geral, possuem alguma regularidade.

Esse tipo de característica coloca em evidência aspectos ligados à vertente "alunos em tempo integral", conforme exposto na primeira seção deste artigo: àquela com uma preocupação voltada apenas para o desenvolvimento do indivíduo (no caso, o aluno) em detrimento de uma visão institucional.

\section{A DEFESA DE UMA ESCOLA SEM A SALA DE AULA: A ASSOCIAÇÃO CIDADE ESCOLA APRENDIZ}

A OSCIP Cidade Escola Aprendiz nasce da iniciativa de Gilberto Dimenstein, jornalista, membro do conselho editorial do jornal Folha de São Paulo e comentarista da Rádio CBN (SP). Nos anos finais da década de 1990, Dimenstein elaborou um projeto experimental no campo da educação com uma escola da rede privada de São Paulo que procurava expandir seus limites de atuação para além dos equipamentos costumeiramente utilizados (a sala de aula, o pátio, o laboratório, a quadra poliesportiva, entre outros).

Esse jornalista partia do pressuposto que o processo educacional não deveria ficar restrito à instituição escolar, principalmente em virtude da necessidade dos alunos que, invariavelmente, se encontravam em situação de falta de concentração e desinteresse em relação às atividades escolares. Dimenstein acreditava que o bairro poderia ser uma fonte interessante de aprendizado: a prática dessa ideia se deu na Vila Madalena, lugar de classe média alta na cidade de São Paulo (Costa, Dimenstein e Semler, 2004).

Com o desenvolvimento desse projeto, no ano de 1998, nesse mesmo bairro, Dimenstein cria a Associação Cidade Escola Aprendiz e lá desenvolve sua perspectiva de uma escola a céu aberto envolvendo crianças e adolescentes de escolas públicas locais em atividades educacionais por diversos pontos do bairro. Essas atividades, para além da revitalização do bairro, buscavam suscitar a identificação dos moradores com as produções realizadas por crianças e jovens: 
Nesse processo de educação e ressignificação dos espaços públicos, diversos atores locais se envolveram fortemente e muitos espaços comerciais passaram a abrir suas portas para a comunidade, transformando-se em verdadeiras salas de aula. (Associação Cidade Escola Aprendiz, s/d., p. 9)

É nesse processo de experimentação e desenvolvimento de uma metodologia própria que, em 2004, o UNICEF reconhece nas atividades desenvolvidas pela Associação Cidade Escola Aprendiz na Vila Madalena a possibilidade de constituição de um modelo aplicável em outras realidades.

Essas atividades consistiam, basicamente, em outra forma de gestão da relação entre a escola e o bairro onde ela encontrava-se localizada, isto é, uma relação de aprendizagem estabelecida com base em dois pressupostos: o de que aprender significa o autoconhecimento e a intervenção no meio onde se vive (espaço, território, bairro etc.); e a de que a educação deve ser vista como uma possibilidade de construção de parcerias (escolas, empresas, poder público, organizações sociais, associações de bairro, indivíduos etc.) para a gestão das potencialidades educativas das comunidades que cercam as escolas (Associação Cidade Escola Aprendiz, s/d.).

Vale destacar que, para o desenvolvimento do Programa Bairro-Escola a Associação Cidade Escola Aprendiz sistematizou suas experiências naquilo que denominou de "tecnologias", por meio de quatro estratégias básicas e indispensáveis para o seu desenvolvimento: a autoformação local; as trilhas educativas; a agência comunitária de notícias; e os territórios culturais (Costa, 2010).

A primeira tecnologia, "autoformação local", partia do pressuposto de que um "grupo articulador local", quando formado por "representantes dos serviços públicos da comunidade" e associado aos "conhecimentos e culturas locais", daria "sustentabilidade" para a política educacional (Djrdjrjan, Garcia e Takahashi, 2010).

É com essa estratégia favorável à territorialização de demandas tipicamente escolares, por meio da auto-organização comunitária, que deve ser entendida a segunda tecnologia proposta pelo Programa Bairro-Escola: "[...] as trilhas educativas, que são caminhos pedagógicos, percursos de aprendizagem nos quais campos diversos do conhecimento se organizam como contextos temáticos, integrando a escola à cidade" (Sardenberg, 2010, p. 22).

Nesse sentido, a Associação Cidade Escola Aprendiz, em seus documentos sobre as tecnologias que compõem o Bairro-Escola, levanta a seguinte questão: "Como é possível articular um território sem que, minimamente, as pessoas saibam o que acontece ali?”. A resposta materializa-se na terceira das tecnologias, as agências comunitárias de notícias: "Assim, o que as Agências propõem é que pessoas de uma mesma comunidade produzam e veiculem informações de interesse local, ao mesmo tempo em que articulam uma rede de comunicação no território" (Rosenfeld, 2010, p. 61).

A defesa de uma educação com bases comunitárias parte do entendimento de que:

Usar e compartilhar os territórios geram pertencimento e relação de comunidade entre as pessoas, que dialogam para construir suas subjetividades. Por 
meio da aprendizagem comunitária, os sujeitos desenvolvem autonomia para ocupar os espaços e se percebem criadores de cultura e não apenas espectadores. (Pazzanese, 2010, p. 29)

Essa ideia defendida pela Associação Cidade Escola Aprendiz, de uma escola para além de seus espaços tradicionais, potencializada por estratégias que se apoiam no conceito de comunidade um tanto quanto genérico, tida como inovadora naquele momento de sua criação, baseava-se na matriz teórica das cidades educadoras, que no Brasil foi incorporada às políticas educacionais, principalmente àquelas com origem na sociedade civil organizada, como uma das alternativas para a ineficácia da escola pública no atendimento das classes populares.

Ocorre que essa incorporação, no âmbito das formulações da Associação Cidade Escola Aprendiz, trouxe consigo um elemento bastante peculiar:

Em meados da década de 70, a UNESCO publicou um relatório chamado Aprender a ser: O relatório Edgar Faure, onde constam 21 teses para a educação do século XXI. Pois o conjunto de tais teses apontava para um ideal, uma utopia: A cidade educativa. Ou seja, nesse documento encontra-se a noção de que a distância entre o lar e a escola não fosse apenas um espaço de ir e vir, mas fosse também um espaço educativo capaz de exercer uma influência construtiva na vida dos educandos. Acho que a cidade escola aprendiz, desenvolvida pelo Gilberto Dimenstein, busca praticar essa utopia. Esse projeto na Vila Madalena, e depois difundido para outros territórios da cidade de São Paulo, traz essa ideia de que é possível capitalizar pedagogicamente tudo o que a cidade oferece - cinemas, museus, bibliotecas, praças, monumentos etc. -, no processo de formação das novas gerações. Hoje a escola de tempo integral é uma ideia ultrapassada, já não faz sentido. O que, sim, faz sentido hoje é a educação o dia inteiro, sem escola o dia inteiro. (Costa, 2004, p. 95, grifo do autor)

Parece haver, no âmbito dessa formulação, uma desconsideração das possibilidades educativas existentes na escola, mais especificamente em uma escola organizada para um funcionamento ampliado, de dia inteiro. Ao mesmo tempo em que são insufladas as potencialidades educativas oriundas da matriz teórica das cidades educadoras nas políticas educacionais voltadas para a população pobre, são esvaziadas as possibilidades existentes na perspectiva da escola de dia inteiro, estruturada de acordo com as peculiaridades necessárias para o seu funcionamento, para essa mesma população.

Essa tendência está relacionada com a vinculação que a Associação Cidade Escola Aprendiz possui com o organismo TPE e com as empresas que dele fazem parte, entre elas: Fundação Itaú Social (único parceiro institucional), Instituto Unibanco, Ambev, Fiat, entre outras. Nessa dimensão, a educação é vista exclusivamente como um negócio, e por isso o problema da ineficiência está vinculado à gestão escolar. 
Considerado uma tecnologia social, o Programa Bairro-Escola é visto como um holding ${ }^{5}$ que é capaz de gerir a comunidade e suas potencialidades educacionais em seu próprio benefício (Costa, 2004). Essa tecnologia não só procura exponenciar as produções existentes nas comunidades, mas também reduzir o papel da escola pública no processo educacional para que outros agentes, principalmente de natureza privada, possam também atuar.

É possível afirmar que a metodologia do Bairro-Escola é vista como uma medida alternativa à escola pública de educação integral em tempo integral, já que, para a Associação Cidade Escola Aprendiz, uma instituição desse tipo monopolizaria a diversidade de atividades educacionais existentes nas comunidades, uma espécie de truste $^{6}$ formado para gerenciar e consequentemente operar no cotidiano escolar.

Esse formato baseado em parcerias proposto pelo Programa Bairro-Escola não significa a quebra do monopólio da escola em relação às atividades educacionais, já que é essa instituição que confere legitimidade para elas. Parece-nos que essa prática demonstra muito mais um desapego pela instituição escolar.

O investimento realizado por essa associação figura no sentido de reinvenção pedagógica da escola pública somente, em nenhum momento outras formas de atuação são mencionadas, como o debate sobre a reestruturação física das escolas públicas, do pagamento de melhores salários a professores e funcionários, entre outros importantes debates que estão diretamente relacionados à efetividade ou não de inovações pedagógicas.

\section{A “ESCOLA CIDADÃ” E SEU ENTENDIMENTO CAMBIANTE DA EDUCAÇÃO INTEGRAL: O INSTITUTO PAULO FREIRE}

A OSCIP Instituto Paulo Freire (IPF) atua prestando assessorias, consultorias, realizando pesquisas, formação (presencial e a distância) inicial e educação continuada para organizações da sociedade civil, a movimentos sociais, a entes federados, às instituições públicas e às fundações de grandes empresas privadas. Foi fundado oficialmente no ano de 1992, seguindo três linhas de atuação: a educação de jovens e adultos, a educação cidadã e a educação popular.

Essa organização é liderada por Moacir Gadotti, importante intelectual, conforme a acepção de Gramsci (2006), do campo da educação que também desenvolve suas atividades como professor da Universidade de São Paulo (USP). Esse intelectual possuía uma forte ligação com Paulo Freire, autor de contribuições inquestionáveis para o pensamento educacional brasileiro.

5 Termo oriundo da língua inglesa utilizado para caracterizar um agrupamento de empresas que possui como objetivo expandir suas atividades produtivas no âmbito do mercado. Uma holding geralmente é constituída para facilitar o controle das atividades em um setor em específico, caso da indústria alimentícia, por exemplo, como uma forma de capitalizar parte considerável desse setor e assim adquirir condições de dominar seu funcionamento.

6 Outro termo oriundo da língua inglesa, utilizado para caracterizar a reunião de empresas com o intuito de expandir suas ações em um setor do mercado. Isso significa a ampliação dos lucros e, por consequência, o domínio desse setor. 
Nessa instituição, as discussões acerca do tema da educação integral são realizadas dentro da tradição teórica da educação popular, que pode ser demarcada, no Brasil, por meio de três iniciativas distintas que se entrecruzam ao longo da história: a educação escolar e as práticas de formação de quadros entre grupos socialistas, anarquistas e os movimentos sociais; o movimento de educadores e intelectuais favoráveis à escola pública universal; e os movimentos e campanhas de alfabetização de adultos.

Segundo Fleuri (1988), no interior desses movimentos era possível identificar uma diferença importante: de um lado, as iniciativas que advinham do Estado que procuravam ampliar o direito à educação escolar ao mesmo tempo em que tutelavam as classes populares como forma de preservação do status quo; de outro lado, as iniciativas que advinham dos movimentos sociais que também pretendiam a ampliação do direito à educação, financiadas por organismos não governamentais, que possuíam o socialismo como estratégia.

Nessa tradição de embates sobre o papel do Estado na educação das classes populares, é criado o conceito de escola pública popular que sustenta a ideia de uma "escola cidadã": autônoma, de formação integral em tempo integral, pública e popular, dirigida pelo Estado na busca pela superação do atraso educacional e aberta participação das organizações da sociedade civil. Segundo Gadotti (1988, p. 8):

Minha posição quanto a este tema fundamental da educação brasileira, e creio também latino-americana, é de que o ensino regular, para ser democrático e popular, deveria ser inteiramente gratuito e universal, de livre acesso a todos, em todos os níveis, público e leigo, criado e mantido pelo Estado, obrigatório em sua fase inicial (não menos de 8 anos), ministrado na escola pública estatal, não burocratizada, mas crítica, criativa, numa palavra, autônoma, isto é, sob a hegemonia da população.

Bordignon e Oliveira (1989) apresentam pela primeira vez esse conceito de uma escola cidadã em artigo publicado na Revista Educação Municipal (1989) editada pela União Nacional dos Dirigentes Municipais de Educação (UNDIME).

Baseando-se principalmente na crítica ao documento constitucional de 1988, que, segundo os autores, apresentava uma relação entre as instâncias de governo (municipal, estadual e federal) articuladas de modo hierárquico, isto é, uma relação baseada na soma dos sistemas educacionais. Pela simples justaposição, esses autores prospectavam a articulação de um sistema nacional de educação pública baseado em uma relação orgânica entre instâncias de governo, como o desafio para a construção da escola cidadã.

Para isso, dois eram os entraves que deveriam ser superados: a própria hierarquia entre as instâncias combinada com um espírito patrimonialista da educação, típicos das administrações que compreendiam as escolas como coisa de governo e não do cidadão.

Afirmavam os autores que a descentralização da educação no país ensejou mais uma tarefa administrativa do que política, mesmo diante da constituição democrática de 1988. Em nenhum momento, o poder decisório no campo da edu- 
cação foi descentralizado para que este pudesse chegar à população de fato; pelo contrário, administrativamente foi transferido para os municípios o poder decisório em relação às suas respectivas redes de ensino, e isso reforçou ainda mais a visão patrimonialista da educação. A variação entre as instâncias era determinada pela importância atribuída ao seu "sistema de ensino", em geral a instância federal era a mais privilegiada.

Diante desse diagnóstico, a proposição da escola cidadã ou a "utopia da escola cidadã” foi assim apresentada:

Como alternativa superadora dos entraves da gestão do sistema de ensino pré-escolar e de $1^{\circ}$ grau, propõe-se uma escola pública única, não pertencente ao governo - seja federal, estadual ou municipal -, mas ao cidadão, e pela qual as três instâncias de governo, e a sociedade civil, sejam igualmente responsáveis, com competências supletivas. A atual divisão das escolas em redes seria substituída pela divisão de encargos e responsabilidades na mesma escola, numa única rede pública, em regime de cogestão com a comunidade. A base física seria, obviamente, o município, enquanto local do exercício da cidadania, não enquanto poder do prefeito. A escola enraizada no lócus onde vive e se educa o cidadão seria a mediadora entre a cultura local e o saber mais amplo, evitando o estreitamento da visão de mundo, pelo localismo, que a torna desenraizada e alienadora. (Bordignon e Oliveira, 1989, p. 11)

É possível notarmos, diante dessas afirmações, que a "escola cidadã” caracteriza-se, em seu momento de elaboração, como uma estratégia de ação progressista no campo da educação em uma realidade de extremo conservadorismo e sucateamento que assolava esse campo nos anos finais da década de 1980, após o período de ditadura militar.

Esse movimento intensificou-se no início dos anos de 1990, quando foram desenvolvidas as primeiras experiências baseadas no conceito de "escola cidadã" em gestões estaduais e municipais, principalmente. É nesse período que Moacir Gadotti publica uma trilogia sobre a concepção da escola cidadã: Uma só escola para todos: caminhos da autonomia escolar (1990), "Escola cidadã: sobre a autonomia da escola" (1992) e "Escola vivida, escola projetada" (1995).

Nessas publicações, o conceito de "escola cidadã" é explorado e aprofundado de acordo com as necessidades que aquele momento determinava. Ao prefaciar a primeira das obras citadas, Florestan Fernandes (1991, p. 12) é preciso nesse diagnóstico:

Assim colocado, o livro constitui um desdobramento da atividade docente. Possui como objetivo ensinar. Como ensinar, porém, no interior de um círculo fechado? Indo ao combate. Destruindo a herança educacional do ensino como privilégio social e a concepção burguesa das funções da educação popular, desvendando suas contradições insuperáveis e os meios para superá-las. Como dizia o educador liberal John Dewey: o fim político da educação é mais educação. Ao contrário, na concepção dialética e popular, o saber adquirido na escola, 
imprescindível para o cumprimento de suas finalidades, não é um fim em si mesmo é um instrumento de luta. O fim da educação numa ótica socialista é a formação da consciência crítica e a organização e a transformação social. Portanto, uma pedagogia não pode se furtar da sua condição de filosofia. Nela, a teoria explica a realidade da escola, ao mesmo tempo em que propõe as práticas para alterá-la radicalmente, de maneira revolucionária.

Todo o debate realizado em torno dessa transformação na concepção da escola pública era centralizado na questão da autonomia de criação, gestão e produção das escolas em relação aos centros de decisão. Por mais que o Estado devesse financiar e regular a educação, a escola pública, ponta do processo democrático, deveria funcionar de acordo com os interesses e demandas próprios da comunidade que dela faz uso. A finalidade do Estado, segundo esses escritos, deveria ser a universalidade do atendimento sem um interesse específico, sendo essa percepção próxima ao conceito de escola unitária de Gramsci (2006). Segundo esse autor, uma escola unitária é aquela que:

[...] requer que o Estado possa assumir as despesas que hoje estão a cargo da família no que toca a manutenção dos escolares, isto é, requer que seja completamente transformado o orçamento do ministério da educação nacional, ampliando-o enormemente e tornando-o mais complexo: a inteira função de educação e formação das novas gerações deixa de ser privada e torna-se pública, pois somente assim ela pode abarcar todas as gerações sem divisões de grupos ou castas. (Gramsci, 2006, p. 36)

Se, durante toda a década de 1980, essa concepção de escola sustentou as ações do IPF, na década seguinte, principalmente após as primeiras experiências da escola cidadã em governos municipais e estaduais, essa concepção foi modificando-se gradativamente. É possível afirmarmos uma mudança de paradigma determinada pelas necessidades de adaptação do conceito de escola cidadã às realidades e burocracias do sistema democrático brasileiro e pelas modificações, ao longo do tempo, ocorridas no próprio conceito de cidadania (Gadotti, 2008).

A escola cidadã de outrora tinha a luta pelos direitos sociais, entre eles a educação pública, como possibilidade estratégica para a ruptura com o modelo capitalista e a instauração de um governo socialista, como antes aqui mostrado; a escola cidadã contemporânea segue o curso da ampliação do conceito de cidadania, não mais visto como estratégico para o socialismo, mas sim para o aperfeiçoamento de um tipo de democracia representativa e com fortes traços de dependência em relação às economias centrais.

Assim como as experiências da escola cidadã desenvolvidas em diversos governos, as modificações ocorridas no conceito de cidadania são fundamentais nesse processo, já que agora esse conceito passa a ser visto pela quantidade de direitos e deveres que os cidadãos possuem, isto é, pela sua capacidade de reivindicação de mais direitos e participação na vida pública, e não por sua condição no mundo da produção. 
É no interior dessa modificação de paradigma que o componente das cidades educadoras, bastante difundido nos anos de 1990, foi incorporado ao conceito de escola cidadã, principalmente pelo fato desse componente possuir em sua essência um sentido múltiplo, tendo em vista que o direito ao espaço urbano significa o direito ao acesso à variedade de serviços que existem em uma cidade, como cultura, lazer, saúde, educação escolar, transporte, entre outros.

Isso retira da escola o enfoque da ação educacional, já que ela não é considerada dentro de sua função específica de transmissão e produção de conhecimento. A concepção ampliada do conceito de cidadania faz com que também se atribua à escola outros tipos de funções, em especial a lógica participativa que afirma estar na instituição escolar a capacidade de organização da parte pauperizada da população para a reivindicação de seus direitos.

O problema dessa perspectiva defendida pelo IPF, por meio de seu fundador, Moacir Gadotti, reside no fato de que aqui, no Brasil, o ciclo de universalização da escola pública, enquanto transmissora e produtora de conhecimento com qualidade e para todos, não se encerrou; pelo contrário, encontra-se em processo e com reconhecida deficiência no cumprimento desse objetivo.

$\hat{E}$ isso que nos possibilita afirmar que a concepção do IPF, que se modificou ao longo dos anos, pode ser compreendida como uma visão que, em vez de fortalecer a estrutura de funcionamento físico, administrativo e pedagógico da escola pública, investe somente nas alternativas pedagógicas como forma de alavancar outros tipos de iniciativas.

Apesar disso, vale ressaltar a preocupação de Gadotti (2009) em diferenciar a "escola cidadã" de experiências contemporâneas que, segundo ele, não levam em consideração ou pouco investem na relação entre as atividades "culturais" e o projeto político-pedagógico das escolas. Essa crítica está direcionada para a concepção de bairro-escola defendida pela Associação Cidade Escola Aprendiz, que, embora seja vista pelo autor como bem-intencionada, esbarra, segundo ele, no reducionismo pedagógico que lhe é peculiar.

Essas críticas são feitas a certas experiências, chamadas de "educação integral" ou de "educação comunitária", e que se limitam a cansar crianças e jovens que ficam perambulando pelas ruas e becos do bairro, frequentando bares e cafés, grafitando muros, colocando cerâmicas nas paredes e realizando outras atividades pontuais e assistemáticas, sem qualquer vínculo com o projeto político-pedagógico da escola e a política educacional da cidade. (Gadotti, 2009, p. 64)

O outro elemento que também demonstra esse movimento cambiante é a localização das discussões a respeito da escola cidadã: após serem iniciadas nos anos de 1980 no âmbito dos movimentos sociais e possuir a bandeira do socialismo enquanto sua finalidade, dos anos $1990 \mathrm{em}$ diante essas discussões passam a figurar com maior intensidade no âmbito dos organismos da sociedade civil, em especial aqueles de base empresarial, que não tinham essa bandeira progressista, pelo contrário. 


\section{CONSIDERAÇÕES FINAIS}

Pelas conclusões disponíveis no final de cada uma das seções deste artigo, é possível validarmos a ideia de que, apesar da predominância da vertente "alunos em tempo integral", o debate no âmbito das discussões sobre o tema da educação integral em tempo integral encontra-se em aberto. Em especial pelo fato da oscilação histórica que existe entre as vertentes. Ora a predominância de uma, ora a predominância de outra.

Apesar disso, a vertente "alunos em tempo integral", especialmente em virtude do contexto político e econômico de seguidas reformas neoliberais, atende apenas às demandas de participação do setor empresarial no campo da educação, expostas por suas organizações da sociedade civil, como vimos, que estão dispostas no âmbito da legislação recente que resultou no Programa Mais Educação.

Essa vertente também atende às demandas de "melhor aproveitamento" dos gastos públicos com a educação, na medida em que ela não direciona seus investimentos para interferir em toda a estrutura de funcionamento da educação pública (física, administrativa e pedagógica). Ao contrário disso, os seus investimentos são direcionados apenas para a dimensão pedagógica que, sem uma associação mais ampla em relação à capacidade de atendimento da escola pública, acabam tornando-se uma nova forma de proselitismo.

\section{REFERÊNCIAS}

Associação Cidade Escola Aprendiz. Bairro-escola: passo a passo. São Paulo: UNICEF; Fundação Educar, s/d.

Bordignon, G.; Oliveira, L. S. M. A escola cidadã: uma utopia municipalista. Revista Educação Municipal, São Paulo: Cortez Editora, ano 2, n. 4, p. 5-13, maio 1989.

Brasil. Lei n. 8.069, de 13 de julho de 1990. Dispõe sobre o Estatuto da Criança e do Adolescente e dá outras providências. Diário Oficial da União, Brasília, DF, 13 jul. 1990. Disponível em: <http://www.planalto.gov.br/ccivil_03/leis/18069.htm>. Acesso em: out. 2014.

. Lei n. 9.394, de 20 de dezembro de 1996. Estabelece as diretrizes e Bases da Educação Nacional. Diário Oficial da União, Brasília, DF, 23 dez. 1996. Disponível em: <http://www.planalto.gov.br/ccivil_03/leis/L9394.htm>. Acesso em: out. 2014.

. Lei n. 9.608, de 18 de fevereiro de 1998. Dispõe sobre o serviço voluntário e dá outras providências. Diário Oficial da União, Brasília, DF, 19 fev. 1998.

.Lei n. 10.172, de 9 de janeiro de 2001. Aprova o Plano Nacional de Educação e dá outras providências. Diário Oficial da União, Brasília, DF, 10 de jan. 2001. Disponível em: <http://www.planalto.gov.br/ccivil_03/leis/leis_2001/110172.htm>. Acesso em: out.2014.

. Lei n. 11.494, de 20 de junho de 2007. Regulamente o FUNDEB, de que trata o art. 60 do ADCT; altera a lei 10.195; revoga dispositivos das leis 9.424/1996, 10.880/2004, e 10.845/2004. Diário Oficial da União, Brasília, DF, 22 jun. 2007a. Disponível em: <http:/www.planalto.gov.br/ccivil_03/_ato2007-2010/2007/Lei/ L11494.htm>. Acesso em: out. 2014. 
Brasil. Decreto n. 6.094, de 24 de abril de 2007. Dispõe sobre a implementação do plano de metas Compromisso Todos pela Educação, pela União Federal, em regime de colaboração com municípios, distrito federal e estados, e a participação das famílias e da comunidade, mediante programas e ações de assistência técnica e financeira, visando à mobilização pela melhoria da qualidade da educação básica. Diário Oficial da União, Brasília, DF, 25 abr. 2007b. Disponível em: <http://www. planalto.gov.br/ccivil_03/_ato2007-2010/2007/decreto/d6094.htm>. Acesso em: out. 2014.

. Portaria normativa interministerial n. 17, de 24 de abril de 2007. Institui o Programa Mais Educação que visa fomentar a educação integral de crianças, adolescentes e jovens, por meio do apoio a atividades socioeducativas no contraturno escolar. Diário Oficial da União, Brasília, DF, 26 abr. 2007c. Disponível em: <www.portal.mec.gov.br>. Acesso em: out. 2014.

. SECAD. MEC. Concep̧̧óes e práticas na educaşão brasileira. Mapeamento das experiências de jornada escolar ampliada no Brasil. Análise quantitativa. Brasília, DF: SECAD; MEC, 2009.

. Decreto n. 7.083, de 27 de janeiro de 2010. Dispõe sobre o Programa Mais Educação. Diário Oficial da União, Brasília, DF, 27 jan. 2010a. Disponível em: <http:// www.planalto.gov.br/ccivil_03/_ato2007-2010/2010/decreto/d7083.htm>. Acesso em: nov. 2014.

Resolução n. 7, de 4 de dezembro de 2010. Fixa Diretrizes Curriculares Nacionais para o Ensino Fundamental de 9 (nove) anos. Diário Oficial da União, Brasília, DF, 9 dez.2010b. Disponível em: <http://portal.mec.gov.br/dmdocuments/rceb007_10. pdf $>$. Acesso em: nov. 2014.

. Parecer CNE/CEB n. 7, de 7 de abril de 2010. Diretrizes Curriculares Nacionais para a Educação Básica. Diário Oficial da União, DF, 9 jul. 2010c. Disponível em: <http://pactoensinomedio.mec.gov.br/images/pdf/pceb007_10.pdf>. Acesso em: 13 out. 2010 .

Resolução CNE/CEB n. 4, de 13 de julho de 2010. Define Diretrizes Curriculares Nacionais Gerais para a Educação Básica. Diário Oficial da União, DF, 14 jul.2010d. Disponível em: <http://portal.mec.gov.br/dmdocuments/rceb004_10.pdf〉. Acesso em: 13 out. 2010.

. INEP. Resumo técnico: Censo escolar 2010. Brasília, DF: MEC; INEP, 2011. Disponível em: <http://portal.inep.gov.br/resumos-tecnicos>. Acesso em: nov. 2014 . INEP. Resumo técnico: Censo escolar 2011. Brasília, DF: MEC; INEP, 2012. Disponível em: <http://portal.inep.gov.br/resumos-tecnicos>. Acesso em: nov. 2014 . INEP. Resumo técnico: Censo escolar 2012. Brasília, DF: MEC; INEP, 2013. Disponível em: <http://portal.inep.gov.br/resumos-tecnicos>. Acesso em: nov. 2014.

. Planejando a próxima década. Conhecendo as vinte metas do Plano Nacional de Educação. Brasília, DF: MEC; SASE, 2014a. Disponível em: <http://pne.mec.gov. br/images/pdf/pne_conhecendo_20_metas.pdf>. Acesso em: nov. 2014. 
Brasil. Lei n. 13.005, de 25 de junho de 2014. Aprova o Plano Nacional de Educação - PNE e dá outras providências. Diário Oficial da União, Brasília, DF, 26 jun. 2014b. Disponível em: <http://www.planalto.gov.br/ccivil_03/_ato2011-2014/2014/lei/113005. htm>. Acesso em: 8 out. 2017.

Cavaliere, A. M. Tempo de escola e qualidade na educação pública. Educação E Sociedade, Campinas: UNICAMP, v. 28, n. 100, p. 1.015-1.035, out. 2007.

. Escolas de tempo integral versus alunos em tempo integral. Em Aberto, Brasília, INEP, v. 22, n. 80, p. 51-63, abr. 2009.

. Políticas especiais no ensino fundamental.In: Fontoura, H. A. (Org.). Políticas públicas, movimentos sociais: desafios à pós-graduação em educação em suas múltiplas dimensões. Rio de Janeiro: ANPEd, 2011.

Cenpec - Centro de Estudos e Pesquisas em Educação, Cultura e Ação Comunitária. Guia de referência: educação integral. São Paulo: CENPEC, 1999.

. Muitos lugares para aprender. São Paulo: CENPEC; Fundação Itaú Social; UNICEF, 2003.

.Educação e cidade. Cadernos CENPEC, São Paulo: CENPEC, n. 1, 2006a. . Educação integral. Cadernos CENPEC, São Paulo: CENPEC, n. 2, 2006b.

. Boletim Educação \& Participação n. 25. São Paulo: CENPEC, 2007a. Disponível em: <http://cenpec.org.br/biblioteca/educacao/producoes-cenpec/boletim-educacaoparticipacao-n-25>. Acesso em: jun. 2012.

. CENPEC: uma história e suas histórias. São Paulo: CENPEC; Imprensa Oficial do Estado de São Paulo, 2007b.

- Avaliação de percurso: fortalecer organizações sociais e induzir políticas de educação integral. São Paulo: CENPEC, 2008.

Tendências para a educação integral. São Paulo: Fundação Itaú Social; CENPEC, 2011.

Coelno, L. M. C. C. História(s) da educação integral. Em Aberto, Brasília, INEP, v. 22, n. 80, p. 83-96, abr. 2009.

Costa, A. C. G.; Dimenstein, G.; Semler, R. Escola sem sala de aula. Campinas: Editora Papirus, 2004.

Costa, N. Apresentação - Bairro-escola: comunidades educativas por uma educação integral. São Paulo: Associação Cidade Escola Aprendiz; Fundação Itaú Social, 2010. (Coleção Tecnologias do Bairro Escola, v. 1).

Cury, C. R. J. Ideologia e educação brasileira: católicos e liberais. São Paulo: Cortez; Autores Associados, 1984.

Delors, J. et al. (Orgs.). Educą̧ão: um tesouro a descobrir. São Paulo: Cortez; Brasília, DF: MEC; UNESCO, 2002.

DJRdjRjan, T. B.; Garcia, A.; TAKahashi, A. S. Intersetorialidade no bairro-escola: rede como método de desenvolvimento local. São Paulo: Associação Cidade Escola Aprendiz; Fundação Itaú Social, 2010. (Coleção Tecnologias do Bairro Escola, v. 1). 
ЕвоLI, T. Uma experiência de educaşão integral. Brasília, DF: INEP; MEC, 1969. Disponível em: <http://www.dominiopublico.gov.br/download/texto/me001840.pdf >. Acesso em: jun. 2012.

FAure, E. Aprender a ser. São Paulo: Difusão Editorial do Livro, 1972.

Fernandes, F. Fracassos programados. 2. ed. In: Gadotti, M. Uma só escola para todos: caminhos da autonomia escolar. Petrópolis: Editora Vozes, 1991. p. 11-14.

Ferreira, D. G. A. Ginásio Estadual Vocacional "Cândido Portinari” de Batatais: história, sujeitos e praticas. 2007. 119f. Dissertação (Mestrado em Educação) - Universidade de São Paulo, São Paulo, 2007.

Fleuri, R. M. As diferentes faces da educação popular. Revista Educação Municipal, São Paulo: Cortez Editora, ano 1, n. 2, p. 22-24, set. 1988.

Fontes, V. O Brasil e o capital: imperialismo: teoria e história. Rio de Janeiro: EPSJV; UFRJ, 2010.

Gadotti, M. Escola pública popular. Revista Educação Municipal, São Paulo: Cortez editora, ano 1, n. 2, p. 5-17, set. 1988.

Vozes, 1991.

. Uma só escola para todos: caminhos da autonomia escolar. Petrópolis: Editora

. Escola cidadã: uma aula sobre a autonomia da escola. São Paulo: Cortez, 1992.

. Escola vivida, escola projetada. Campinas: Papirus, 1995.

. Escola cidadã. São Paulo: Cortez Editora, 2008.

. Educação integral no Brasil: inovações em processo. São Paulo: Editora e Livraria Instituto Paulo Freire, 2009.

Gramsci, A. Cadernos do cárcere: os intelectuais. O princípio educativo. Jornalismo. Rio de Janeiro: Editora Civilização Brasileira, 2006. v. 2.

. Cadernos do cárcere: notas sobre o Estado e a política. Rio de Janeiro: Editora Civilização Brasileira, 2007.v. 3.

Martins, A. S. Burguesia e a nova sociabilidade: estratégias para educar o consenso no Brasil contemporâneo. 2007. 293f. Tese (Doutorado em Educação) - Universidade Federal Fluminense, Niterói, 2007.

Pazzanese. R. E. Uma perspectiva para a expressão coletiva. São Paulo: Associação Cidade Escola Aprendiz; Fundação Itaú Social, 2010. (Coleção Tecnologias do Bairro Escola, v. 4).

Ribeiro, D. O livro dos CIEPs. Rio de Janeiro: Bloch Editores, 1986.

Rosenfeld, M. As agências comunitárias de notícia. São Paulo: Associação Cidade Escola Aprendiz; Fundação Itaú Social, 2010. (Coleção Tecnologias do Bairro Escola, v. 3).

Sardenberg, A. Trilhas educativas: o diálogo entre o território e a escola. São Paulo: Associação Cidade Escola Aprendiz; Fundação Itaú Social, 2010. (Coleção Tecnologias do Bairro Escola, v. 2).

Saviani, D. Plano de desenvolvimento da educação: análise do projeto do MEC. Educação E̊ Sociedade, Campinas: UNICAMP, v.. 28, n. 100, p. 1.231-1.255, out. 2007. 
Silva, B. A. R. Interesses, dilemas e a implementação do Programa Mais Educação no município de Maricá (RJ). 2013. 275f. Tese (Doutorado em Educação) - Universidade Federal do Rio de Janeiro, Rio de Janeiro, 2013.

Teixeira, A. Educação para a democracia: introdução a administração educacional. Rio de Janeiro: Editora UFRJ, 1997.

\section{SOBRE O AUTOR}

Bruno Adriano Rodrigues da Silva é doutor em educação pela Universidade Federal do Rio de Janeiro (UFRJ). Professor da Universidade Federal de Lavras (UFLA).

E-mail:bruno.rodrigues@def.ufla.br

Recebido em 21 de maio de 2015

Aprovado em 9 de março de 2016 